\title{
Poli(Álcool Vinílico) Modificado com Cadeias Hidrocarbônicas: Avaliação do Balanço Hidrófilo/Lipófilo
}

\author{
Isabele B. Aranha, Elizabete F. Lucas \\ Instituto de Macromoléculas Professora Eloisa Mano, UFRJ
}

Resumo: Terpolímeros de poli(álcool vinílico) foram sintetizados por meio de reação de esterificação do PVA parcialmente hidrolisado com cloretos de ácidos graxos de comprimento de cadeia diferentes. O objetivo da síntese foi obter polímeros à base de PVA com pequenas variações no balanço hidrófilo/lipófilo e nas propriedades interfaciais de suas soluções. A modificação foi acompanhada por ressonância magnética nuclear de hidrogênio e as propriedades foram avaliadas pela variação na solubilidade e na tensão superficial. Foram obtidos polímeros modificados com baixos teores de grupamento hidrófobo. Testes de tensão superficial, realizados com os produtos solúveis em água, não mostraram variação dessa propriedade. A solubilidade dos produtos diminuiu sensivelmente mesmo para pequenas incorporações de grupamento hidrófobo. Foi observado que, para uma mesma massa, segmentos hidrófobos menores, distribuídos ao longo da cadeia, promovem maior modificação na solubilidade.

Palavras-chave: Poli(álcool vinílico), ácidos graxos, esterificação, solubilidade.

\section{Chemical Modification of Poly(Vinyl Alcohol): Evaluation of Hydrophilic/Lipophilic Balance}

\begin{abstract}
Poly(vinyl alcohol) terpolymers have been obtained by reaction of partially hydrolized poly(vinyl alcohol) with different acid chlorides. The objective is the preparation of polymers with slight differences in their hydrophilic/lipophilic balance and in the interfacial activities of their solutions. The chemical modifications were characterized by means of ${ }^{1} \mathrm{H}$ NMR and the polymer properties were evaluated in terms of changes in solubility and surface tension. By chemical modification, polymers with low percentage of hydrophobic group were obtained. The water-soluble polymers obtained did not have the surface tension of their solutions altered. The solubility of the modified polymers decreased markedly, even with low contents of hydrophobic groups.
\end{abstract}

Keywords: Poly(vinyl alcohol), fatty acids, esterification, solubility.

\section{Introdução}

Nos últimos anos, o estudo de polímeros anfifílicos solúveis em água tem sido de muito interesse. Pesquisas nesta área têm sido direcionadas para a síntese e avaliação de propriedades em solução de polímeros hidrofobicamente modificados, os quais são caracterizados pela presença de sítios hidrófobos, pela alta atividade superficial e pelo acentuado aumento da viscosidade de soluções aquosas. Estes polímeros são de interesse em diversas aplicações comerciais importantes, tais como, floculação, aumento da recuperação de petróleo (ou recuperação melhorada de petróleo), fluidos hidráulicos, redutor de fricção e tintas látex ${ }^{[1]}$.

Polímeros contendo grupos hidrófobos, solúveis em água, podem ser obtidos por meio de modificação química, por copolimerização ou por ambos os métodos. A modificação química tem sido empregada, principalmente, aos derivados da celulose e do

Autor para correspondência: Elizabete F. Lucas, Instituto de Macromoléculas Professora Eloisa Mano, UFRJ, bl.J, IIha do Fundão, CEP: 21945-970, Rio de Janeiro, RJ. E-mail: elucas@ima.ufrj.br 
amido, ao poli(óxido de etileno) e ao poli(ácido acrílico). A copolimerização tem sido empregada para derivados da poliacrilamida ${ }^{[2]}$. Como exemplo da combinação de uso da modificação química e da copolimerização, pode ser citada a obtenção da poliacrilamida sulfonada ${ }^{[3]}$.

\section{O poli(álcool vinílico)}

O poli(álcool vinílico) (PVA) é a resina sintética, solúvel em água, produzida em maior volume no mundo. Foi obtido pela primeira vez em 1924, por Herrman e Haehnel, pela hidrólise do poli(acetato de vinila), que é a forma de obtenção comercial utilizada até hoje. Em 1961, Staudinger estudou a transformação reversível entre o poli(álcool vinílico) e o poli(acetato de vinila) por meio das reações de esterificação e saponificação ${ }^{[4]}$.

As propriedades básicas do poli(álcool vinílico) dependem do grau de polimerização e do grau de hidrólise. Por suas excelentes propriedades, o PVA tem sido utilizado em um grande número de aplicações industriais. Este polímero é um excelente adesivo, possui boa resistência a solventes, óleos e graxas e sua resistência a passagem de oxigênio é superior a de qualquer polímero conhecido ${ }^{[4]}$. É um dos poucos polímeros semicristalinos solúveis em água com boas características interfaciais e mecânicas. O PVA tem sido usado em processamento de papel e fibras e como estabilizante de emulsão, além de ser importante como matéria-prima para filmes. Estudos de obtenção de PVA vêm sendo desenvolvidos para controle da cristalinidade e, pela introdução de grupos funcionais, para melhorar ou conferir propriedades específicas.

O PVA tem sido amplamente utilizado em fibras, adesivos, emulsificantes, em aplicações na indústria têxtil e de papel, como protetor de colóide ${ }^{[5]}$, na obtenção de membranas anfifílicas para imobilização de enzimas ${ }^{[6]}$ e na obtenção do poli(vinil butiral) ${ }^{[4]}$. Mais recentemente, o PVA tem sido utilizado como carreador de medicamento, devido às suas propriedades de degradabilidade e não toxidez ${ }^{[7]}$. Algumas aplicações visam alterar a permeabilidade a gases ${ }^{[4]}$, aumentar a processabilidade e a resistência térmi$\mathrm{ca}^{[7,8]}$, a capacidade de estabilização de dispersões ${ }^{[8]}$, a biocompatibilidade ${ }^{[8]}$, a permeabilidade e a biode$\operatorname{gradabilidade}^{[9]}$.

O grande número de aplicações do PVA levou a uma variedade de produtos comerciais. Estes produtos são classificados, quanto ao grau de hidrólise, em parcialmente hidrolisados e completamente hidrolisados; e quanto ao grau de polimerização, em baixa viscosidade $(5 \mathrm{cp})$, média viscosidade $(20-30 \mathrm{cp})$ e alta viscosidade $(40-50 \mathrm{cp})^{[8]}$.

\section{Comportamento quanto à solubilidade}

O poli(álcool vinílico) é usado principalmente em solução. É solúvel em solventes altamente polares e hidrófilos, tais como dimetilsulfóxido (DMSO), acetamida, glicóis, dimetilformamida (DMF), sendo a água o melhor solvente. As soluções de PVA em misturas DMSO-água são instáveis e tornam-se túrbidas em repouso. Usando-se $3 \mathrm{~g} / \mathrm{L}$ de PVA em DMSO-água $(6: 4)$ a $30^{\circ} \mathrm{C}$, a taxa de crescimento da turvação é proporcional ao grau de polimerização e é dependente da regularidade estrutural do $\mathrm{PVA}^{[8]}$. A solubilidade em água depende do grau hidrólise, do grau de polimerização e da temperatura da solução.

No PVA completamente hidrolisado, o elevado número de hidroxilas leva à formação de ligações de hidrogênio fortes entre grupos hidroxilas intra- e intermoleculares, impedindo sua solubilização em água. Isto explica porque o PVA completamente hidrolisado é insolúvel a frio. Por outro lado, os grupos acetato residuais no PVA parcialmente hidrolisado são essencialmente hidrófobos e enfraquecem as ligações intra- e inter-moleculares dos grupos hidroxila vizinhos. Portanto, a presença de uma quantidade adequada de grupos acetato aumenta a solubilidade em água, a frio ${ }^{[8]}$. A solubilização do PVA (100\% hidrolisado) em água requer temperaturas elevadas devido à alta energia associada à dissolução da fase cristalina. Após a dissolução, o PVA mantém-se em solução aquosa mesmo em temperatura ambiente.

Além disso, o efeito da temperatura na solubilidade está associado à quebra das ligações de hidrogênio intra- e inter-moleculares. Com o aumento da temperatura, as ligações de hidrogênio são rompidas diminuindo as forças intra-e inter-moleculares e, com isso, a solubilidade aumenta. Por outro lado, o aumento da temperatura pode quebrar também as ligações de hidrogênio com a água diminuindo a solubilidade.

Para o PVA 98\% hidrolisado, a solubilidade aumenta com a diminuição do grau de polimerização. Para o PVA parcialmente hidrolisado (88\%), a solubilidade é relativamente independente do grau de polimerização. E para o PVA $80 \%$ hidrolisado, a solubilidade a baixa 
temperatura é muito maior que para o $88 \%$ hidrolisado, mas decresce rapidamente a partir de $30^{\circ} \mathrm{C}$.

Este trabalho tem como objetivo sintetizar polímeros anfifílicos (PVA modificado), caracterizálos estruturalmente e avaliar seu comportamento quanto a variações no balanço hidrófilo/lipófilo (HLB). Foram utilizados os ácidos carboxílicos láurico (C12) e esteárico (C18), para a modificação do PVA.

\section{Experimental}

\section{Materiais}

Os ácidos esteárico e láurico (AGF, grau de pureza de $98 \%$ ) foram usados após secagem sob vácuo por 24 horas. O cloreto de tionila (Fluka, grau de pureza de 99\%) e o poli(álcool vinílico) (PVA) foram usados sem purificação adicional.

\section{Caracterização dos reagentes: ácidos graxos e} poli(álcool vinílico)

Os ácidos graxos foram caracterizados quanto à estrutura por ressonância magnética nuclear de hidrogênio ( $\left.\mathrm{H}^{1}-\mathrm{NMR}\right)$, utilizando um equipamento Varian Gemini-300. A solubilidade desses ácidos foi testada com adição de $10 \mathrm{~mL}$ de cloreto de tionila e $1 \mathrm{~g}$ do ácido carboxílico, sob agitação magnética.

O PVA foi caracterizado quanto à massa molar, grau de hidrólise e solubilidade. A massa molar foi determinada por viscosimetria ${ }^{[10]}$, utilizando a equação de MarkHouwink-Sakurada $^{[11]}$ (realizada em um reômetro Contraves low shear, LS 40). A faixa de cisalhamento utilizada foi de 40 a $100 \mathrm{~s}^{-1}$ e a temperatura da análise foi de $30^{\circ} \mathrm{C}$. O grau de hidrólise foi determinado também por ressonância magnética nuclear de hidrogênio ( $\mathrm{H}^{1}$-NMR), utilizando a relação de áreas do próton alfa do poli(álcool vinílico) e do próton alfa do acetato de vinila. Os deslocamentos químicos de ${ }^{1} \mathrm{H}$ foram referenciados no DMSO- $d_{6}\left(\mathrm{~d}_{\mathrm{H}} 2,62\right)$.

A solubilidade em diversos solventes foi avaliada adicionando-se $10 \mathrm{mg}$ do polímero em $2 \mathrm{~mL}$ do solvente, a frio. Após 24 horas, os sistemas insolúveis foram aquecidos até uma temperatura máxima, limitada pelo ponto de ebulição de cada solvente.

\section{Modificação química do poli(álcool vinílico)}

A modificação do PVA foi feita em duas etapas: a formação de cloreto de acila e a esterificação do polímero por meio da reação de Schotten- Baumann ${ }^{[12]}$.
Os cloretos de acila foram obtidos a partir dos ácidos carboxílicos láurico e esteárico, utilizando cloreto de tionila como agente de acilação.

Primeiramente, o PVA foi seco em estufa a vácuo, a temperatura de $50^{\circ} \mathrm{C}$, até ser atingida massa constante, e mantido em dessecador. A N,Ndimetilformamida foi destilada a $153^{\circ} \mathrm{C}^{[13]} \mathrm{e}$ mantida em peneira molecular $4 \AA$, por 48 horas.

Para obtenção dos cloretos de acila, foram colocados para reagir $40 \mathrm{~g}$ do ácido carboxílico e $120 \mathrm{~mL}$ de cloreto de tionila, durante três horas, em temperatura ambiente, sob agitação magnética e fluxo de nitrogênio. A purificação dos cloretos de acila obtidos foi feita por meio de destilação à vácuo bulbo a bulbo e verificada por meio de sua solubilidade em N,Ndimetilformamida (DMF).

Antes da reação, o PVA foi solubilizado em DMF, por meio de aquecimento a $85^{\circ} \mathrm{C}$ por duas horas, sob agitação magnética e fluxo de nitrogênio, e posteriormente resfriado a temperatura ambiente. A reação de esterificação foi realizada a temperatura de $80^{\circ} \mathrm{C}$, sob atmosfera de nitrogênio e forte agitação. Primeiramente foi adicionada a solução de PVA $(8 \%$ $\mathrm{m} / \mathrm{v}$ ), seguida da adição do cloreto de acila e, então, de duas gotas de piridina. A agitação foi mantida por 5 horas. O produto modificado foi separado do meio reacional por precipitação em acetato de etila e secagem, em estufa a vácuo $\left(50^{\circ} \mathrm{C}\right)$, por 24 horas.

\section{Caracterização do poli(álcool vinílico) modificado}

O percentual molar de incorporação do grupo hidrófobo na cadeia do PVA foi obtido por $\mathrm{H}^{1}$-NMR. Foi utilizada a seguinte notação, ilustrada na Figura 1: $\mathbf{A}=$ mero acetato, $\mathbf{O}=$ mero hidrolisado e $\mathbf{E}=$ mero esterificado. A incorporação do cloreto de acila foi calculada usando a integral em $0,9 \mathrm{ppm}$ do grupo $\mathrm{CH}_{3}$ terminal, a integral de $\mathrm{H}_{\alpha}(\mathrm{A}+\mathrm{E})$ em $\sim 5,0$ ppm e a integral em 2,0-0,5 ppm dos grupos $\mathrm{CH}_{2}(\beta)$ de $\mathrm{A}$, $\mathrm{O}$ e E, além da parte alquila do éster incorporada no PVA.

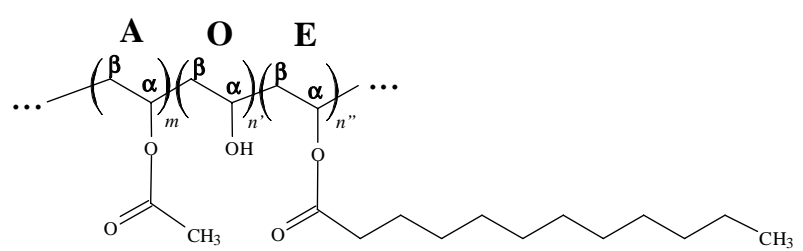

Figura 1. Estrutura do PVA modificado. $\mathrm{A}=$ mero acetato, $\mathrm{O}=$ mero hidrolisado e $\mathrm{E}=$ mero esterificado. 
A avaliação da solubilidade foi feita adicionandose $10 \mathrm{mg}$ do polímero modificado em $2 \mathrm{~mL}$ de água, à temperatura ambiente. $\mathrm{O}$ teste de solubilidade em DMF foi realizado em função da temperatura, aquecendo-se o sistema a uma taxa de aproximadamente $2^{\circ} \mathrm{C} / \mathrm{min}$, até $90^{\circ} \mathrm{C}$. Deste modo foi determinada a temperatura de completa solubilização do polímero.

As medidas de tensão superficial das soluções aquosas poliméricas foram realizadas em tensiômetro Krüss modelo K10, pelo método do anel de Du Noüy, à temperatura de $30^{\circ} \mathrm{C}$. Foram preparadas soluções aquosas nas concentrações percentuais $(\mathrm{p} / \mathrm{v})$ de 0,$5 ; 0,2 ; 0,1 ; 0,02$ e 0,01 . Os valores colocados em gráfico representam a média de 3 medidas com precisão de $\pm 0,1 \mathrm{mN} / \mathrm{m}$.

\section{Resultados e Discussão}

\section{Caracterização do poli(álcool vinílico)}

O grau de hidrólise do poli(álcool vinílico) é um fator essencialmente importante, pois dele dependem todas as suas propriedades. Por meio da análise de seu espectro de ressonância magnética nuclear foi obtido um grau de hidrólise de $80 \%$.

A massa molar do PVA foi determinada por viscosimetria. A taxa de cisalhamento de $60 \mathrm{~s}^{-1}$ foi escolhida para a determinação da viscosidade intrínseca devido ao comportamento Newtoniano apresentado pela solução polimérica nesta taxa. A determinação da viscosidade intrínseca foi baseada na extrapolação, a concentração zero, da reta obtida por ajuste matemático dos pontos experimentais da curva da viscosidade reduzida em função da concentração da solução. A viscosidade intrínseca obtida foi de $0,8791 \mathrm{dL} / \mathrm{g}$. A massa molar foi calculada por meio da equação de Mark-Houwink-Sakurada, utilizando os valores de K e tabelados em Handbook ${ }^{[11]}: 42,8$ mL/g e 0,64 , respectivamente.

A solubilidade do PVA foi testada em diversos solventes. A solubilidade do PVA em água é resultante da capacidade do polímero formar pontes de hidrogênio com a água. À medida que o grau de hidrólise aumenta, prevalecem as ligações de hidrogênio intra- e intermoleculares, dificultando as ligações com as moléculas de água, consequentemente diminuindo sua solubilidade. O PVA utilizado apresenta um grau de hidrólise de $80 \%$, e a presença dos grupos acetato diminui as interações intra- e intermoleculares, favorecendo a entrada da água nos novelos poliméricos, sendo, portanto, solúvel a frio, sem que seja necessário aquecer previamente, como ocorre com o PVA $100 \%$ hidrolisado. Os demais solventes testados foram escolhidos com base nos valores de seus parâmetros de solubilidade, os quais deveriam estar próximos ao valor de parâmetro de solubilidade $(\delta)$ do PVA, isto é, 12,6 $\left(\mathrm{cal} / \mathrm{cm}^{3}\right)^{1 / 2[14]}$. Assim, foram testados acetona $(9,9)$, clorofórmio $(9,3), \mathrm{N}, \mathrm{N}$-dimetilformamida (DMF) $(12,1)$, dimetilsulfóxido (DMSO) $(12,0)$, etanol $(12,7)$, isopropanol $(11,5)$ e N-metilpirrolidona (NMP) $(11,3)$ [os valores entre parêntesis correspondem aos respectivos parâmetros de solubilidade expressos em $\left.\left(\mathrm{cal} / \mathrm{cm}^{3}\right)^{1 / 2}\right]^{[14]}$. Entre estes solventes, o PVA apresentou-se solúvel somente em NMP à temperatura ambiente, e em DMF e DMSO a quente. A DMF foi escolhida como solvente para o PVA por manter o polímero em solução após resfriamento (o que não ocorria usando DMSO) e por ser um solvente menos tóxico que a NMP.

\section{Caracterização dos ácidos graxos}

Os ácidos graxos foram analisados por ressonância magnética nuclear de hidrogênio ( $\left.\mathrm{H}^{1}-\mathrm{NMR}\right)$ para confirmação de suas estruturas químicas. Os espectros apresentaram picos característicos de ácido graxo e o comprimento da cadeia foi calculado com base na razão entre a área total dos prótons metilênicos e a dos prótons metílicos, multiplicada por $3 / 2$. Os valores encontrados foram de 11 e 17 unidades metilênicas, confirmando as estruturas dos ácidos láurico (C12) e esteárico (C18), respectivamente.

Quanto à solubilidade dos ácidos graxos em DMF, solvente escolhido para o PVA, estes foram prontamente solúveis à temperatura ambiente.

\section{Modificação química do poli(álcool vinílico)}

O PVA foi modificado quimicamente por meio da reação de esterificação de Scotten-Baumann, o que garante um produto mais puro e a possibilidade de realizar a reação em baixas temperaturas. No entanto, foram obtidos baixos rendimentos, principalmente devido à hidrólise de cloreto de ácido durante o manuseio.

A DMF foi escolhida como solvente para a reação pelo fato de solubilizar ambos os reagentes e ser menos tóxica, entretanto seu elevado ponto de ebulição $\left(153^{\circ} \mathrm{C}\right)$ dificultou sua eliminação após a reação.

O produto da reação foi separado por precipitação em um não-solvente, a metil etil cetona. 


\section{Caracterização do polímero modificado}

Determinação da composição

Os polímeros modificados, assim como o poli(álcool vinílico) puro, foram analisados por ressonância magnética nuclear de hidrogênio ( ${ }^{1}$-NMR). As Figuras 2 e 3 mostram os espectros do PVA e do PVA modificado com 4,3\% molar de grupo hidrófobo (cloreto de lauroíla), respectivamente. No espectro do PVA observa-se uma superposição de picos em 1,5 ppm, correspondente aos prótons metilênicos $\beta$ do acetato de vinila e do álcool vinílico; um triplete em 2,1 ppm correspondente aos prótons metílicos $\left(\mathrm{CH}_{3}\right)$ do acetato de vinila; um singlete em 4,0 ppm correspondente ao próton $\alpha$ do álcool vinílico; um triplete em 4,5 ppm correspondente ao próton da hidroxila do álcool vinílico; em os prótons a $\delta$ acetato de etila em 5 ppm.

No espectro do poli(álcool vinílico) modificado com teor de incorporação do grupo hidrófobo (cloreto de lauroíla) de 4,3\% molar, observa-se um triplete em $0,9 \mathrm{ppm}$ correspondente ao $\mathrm{CH}_{3}$ da cadeia hidrocarbônica longa (grupo hidrófobo). Os prótons $\alpha$ do éster de cadeia longa e do acetato de vinila aparecem na mesma região, em $5 \mathrm{ppm}$. Na região de 1,3 a 1,9 ppm também encontram-se superpostos os prótons $\beta$ do álcool vinílico, do acetato de vinila e do éster de cadeia longa. Os sinais em 2,85 e 3,05 ppm são correspondentes a $\mathrm{N}, \mathrm{N}$ dimetilformamida, que foi o solvente utilizado na reação e que deve ter ficado retido na estrutura do polímero.

Baseando-se no princípio de que as áreas dos picos são diretamente proporcionais aos números de

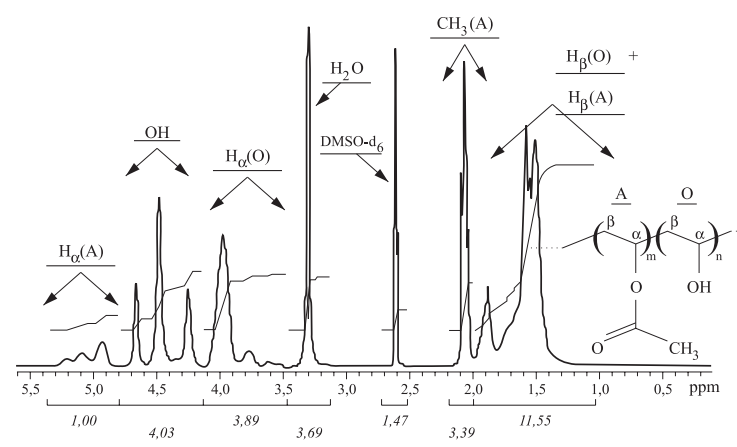

Figura 2. Espectro de ressonância magnética nuclear de hidrogênio do poli(álcool vinílico). $\mathrm{A}=$ mero acetato e $\mathrm{O}=$ mero hidrolisado

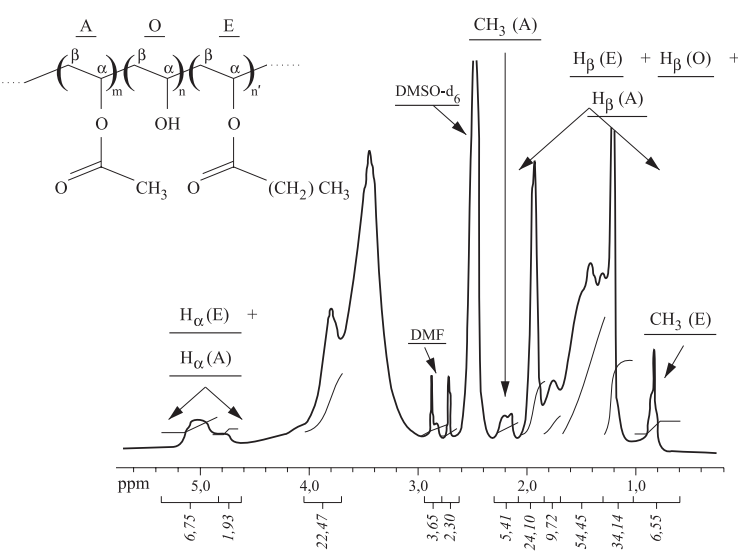

Figura 3. Espectro de ressonância magnética nuclear de hidrogênio para o PVA modificado com 4,3 \% de incorporação de cloreto de lauroíla. A $=$ mero acetato, $\mathrm{O}=$ mero hidrolisado e $\mathrm{E}=$ mero estereficado

hidrogênios que aparecem na referida região, a relação dos meros (de álcool vinílico, acetato de vinila e éter de cadeia longa) foi determinada (Tabela 1).

É importante observar que os teores de grupo hidrófobo incorporados foram inferiores àqueles utilizados na alimentação da reação de modificação, o

Tabela 1. Valores percentuais molares dos meros constituintes do PVA e dos PVA's modificados.

\begin{tabular}{|c|c|c|c|c|c|}
\hline \multirow{2}{*}{ Produto } & \multirow{2}{*}{$\begin{array}{c}\text { Ácido graxo } \\
\text { utilizado }\end{array}$} & \multirow{2}{*}{$\begin{array}{l}\text { \% molar de } \\
\text { ácido graxo na } \\
\text { alimentação }\end{array}$} & \multicolumn{3}{|c|}{$\%$ molar dos meros* } \\
\hline & & & Álcool vinílico & $\begin{array}{l}\text { Acetato } \\
\text { de vinila }\end{array}$ & $\begin{array}{c}\text { Éster de } \\
\text { cadeia longa }\end{array}$ \\
\hline PVA & - & - & 81,59 & 18,41 & - \\
\hline PVAL1 & & 0,1 & 81,55 & 18,41 & 0,04 \\
\hline PVAL2 & & 0,25 & 81,61 & 18,28 & 0,11 \\
\hline PVAL3 & Láurico & 0,50 & 83,92 & 15,81 & 0,27 \\
\hline PVAL4 & & 1,0 & 79,45 & 19,95 & 0,60 \\
\hline PVAL5 & & 10,0 & 82,60 & 13,10 & 4,30 \\
\hline PVAE1 & Esteárico & 1,0 & 85,32 & 14,21 & 0,46 \\
\hline
\end{tabular}

* Determinado por $\mathrm{H}^{1}-\mathrm{NMR}$. 
que evidencia o baixo rendimento da reação. Este fenômeno pode estar relacionado a algum grau de decomposição dos cloretos de acila por hidrólise, durante o manuseio ou provocada pela umidade presente no polímero, uma vez que o solvente da reação foi destilado e armazenado em peneira molecular, e a reação foi conduzida sob atmosfera de nitrogênio seco. Também pode ser observada uma pequena variação no teor de acetato de vinila, provavelmente devido à hidrólise que ocorreu durante a reação de esterificação.

\section{Avaliação da solubilidade}

A Tabela 2 apresenta o resultado dos testes de solubilidade, em água e na temperatura ambiente, dos polímeros modificados. Observa-se que pequenas incorporações da cadeia hidrocarbônica tornam o PVA insolúvel em água. Para o polímero modificado em ácido láurico, incorporações baixas, como 0,27\% molar, já tornam o PVA insolúvel. Isto significa que uma pequena variação no número de hidroxilas, altera sensivelmente o balanço hidrófilo/lipófilo (HLB) do PVA, uma vez que as cadeias hidrocarbônicas incorporadas são altamente hidrófobas.

Os testes de solubilidade em temperatura ambiente indicam somente a partir de que grau de incorporação o polímero torna-se insolúvel. Entretanto, como o objetivo do trabalho é avaliar a variação de comportamento em função do grau de modificação, foram realizados testes de solubilidade em função da temperatura. Para estes testes foi utilizada a DMF como solvente, devido a seu ponto de ebulição ser superior ao da água $\left(153^{\circ} \mathrm{C}\right)$. Os resultados apresentados na Tabela 3 mostram que um aumento no percentual molar de grupamento hidrófobo provoca
Tabela 2. Solubilidade, em água, dos polímeros modificados (temperatura ambiente).

\begin{tabular}{cccc}
\hline Produto & $\begin{array}{c}\text { Origem da } \\
\text { cadeia } \\
\text { hidrófoba }\end{array}$ & $\begin{array}{c}\% \text { molar de } \\
\text { grupo } \\
\text { hidrófobo }\end{array}$ & $\begin{array}{c}\text { Solubilidade } \\
\text { em água }\end{array}$ \\
\hline $\begin{array}{c}\text { PVA (80\% } \\
\text { hidrolisado) }\end{array}$ & - & - & Solúvel \\
\hline PVAL1 & & 0,04 & Solúvel \\
PVAL2 & Ácido láurico & 0,27 & Insolúvel \\
PVAL3 & 0,11 & Solúvel \\
PVAL4 & & 0,60 & Insolúvel \\
PVAL5 & & 4,30 & Insolúvel \\
\hline PVAE1 & Ácido esteárico & 0,46 & Insolúvel \\
\hline
\end{tabular}

um aumento da temperatura em que o polímero é solubilizado.

Para percentuais de até $0,6 \%$ de ácido láurico incorporado, o polímero foi completamente solúvel em DMF. Para uma incorporação de $4 \%$, o PVA modificado com ácido láurico foi parcialmente solúvel até uma temperatura de $120^{\circ} \mathrm{C}$. Isto evidencia a diminuição da solubilidade pela introdução de grupos apolares (cadeias hidrocarbônicas).

O polímero obtido pela modificação em $0,46 \%$ molar (3,38 \% em massa) de ácido esteárico apresentou menor temperatura de solubilização que aquele obtido pela incorporação de 0,6 \% molar (3,08 \% em massa) de ácido láurico. Esperava-se que para um maior percentual em massa, a temperatura de solubilização fosse maior. Porém, comparando-se os produtos PVAL4 e PVAE1, observa-se que para o maior percentual em massa obteve-se menor temperatura de solubilização. A redução do número de hidroxilas também é um fator que contribui para

Tabela 3. Avaliação dos polímeros modificados quanto à solubilidade, em DMF, em função da temperatura.

\begin{tabular}{ccccc}
\hline Produto & $\begin{array}{c}\text { Origem da cadeia } \\
\text { hidrófoba }\end{array}$ & $\begin{array}{c}\text { \% molar de cadeia } \\
\text { hidrófoba }\end{array}$ & $\begin{array}{c}\text { \% em massa de } \\
\text { cadeia hidrófoba }\end{array}$ & $\begin{array}{c}\text { T }\left({ }^{\circ} \mathbf{C}\right) \\
\mathbf{\pm 1}\end{array}$ \\
\hline PVA & - & 0,00 & 0,00 & 70 \\
PVAL1 & Ácido láurico & 0,04 & 0,21 & 76 \\
PVAL2 & 0,11 & 0,57 & 84 \\
PVAL4 & 0,60 & 3,08 & $120^{*}$ \\
PVAL5 & Ácido esteárico & 0,46 & 20,55 & 79 \\
\hline
\end{tabular}

Concentração da solução polimérica $=0,5 \% \mathrm{p} / \mathrm{v}$.

* Parcialmente solúvel a $120^{\circ} \mathrm{C}$. 
reduzir a solubilidade, entretanto não se pode afirmar que essa pequena variação tenha sido a única responsável pelo resultado observado. Uma outra explicação pode ser sugerida com base na forma como os grupos hidrófobos estão distribuídos ao longo da cadeia de polímero: segmentos mais curtos, distribuídos ao longo da cadeia, estariam promovendo maior modificação na solubilidade.

\section{Tensão superficial}

A influência das reações de modificação química sobre as propriedades do polímero também foi verificada em termos de tensão superficial de suas soluções aquosas. A atividade superficial do poli(álcool vinílico) é fortemente influenciada pelo balanço hidrófilo/lipófilo. A presença de grupos hidrófobos na molécula favorece a adsorção na interface líquido-gás, pois estes tendem a migrar para a superfície da solução, a fim de minimizar o contato com a fase aquosa. Portanto, a modificação realizada deveria diminuir a tensão superficial das soluções aquosas. No entanto, não foram observadas diferenças na tensão superficial, em solução aquosa, para o PVAL2 quando comparado ao PVA, como mostra a Figura 4. A determinação da tensão superficial não se mostrou eficaz para a caracterização da atividade superficial dos polímeros modificados; o teor de cadeia hidrófoba incorporada, que ainda permite a solubilização do polímero em água, não foi suficiente para provocar uma modificação significativa na tensão superficial, provavelmente devido à distribuição aleatória dessas cadeias e a seu curto tamanho comparado ao da cadeia principal.

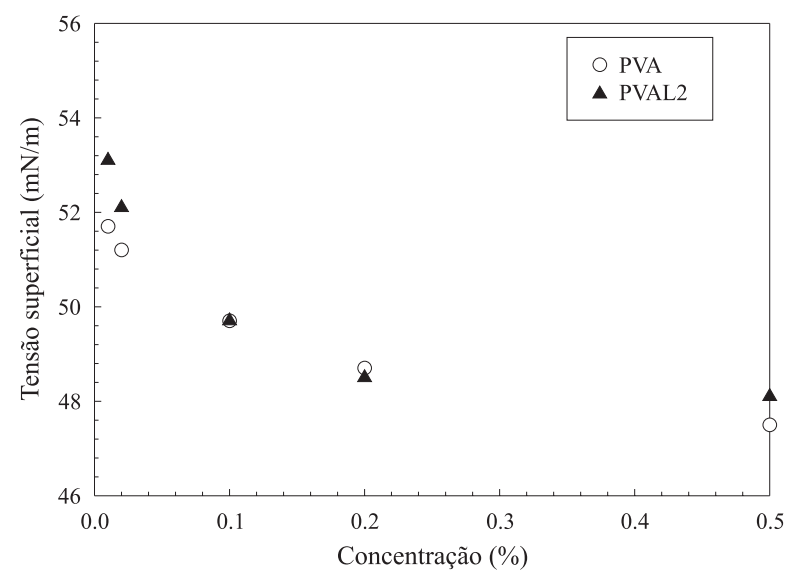

Figura 4. Tensão superficial das soluções aquosas dos polímeros PVA e PVAL2.

\section{Conclusões}

As reações de modificação não apresentaram o rendimento esperado, possivelmente devido à hidrólise de parte dos cloretos de acila utilizados. Entretanto, foram obtidos polímeros com teores de incorporação variados, os quais puderam ser avaliados quanto à variação em seu balanço hidrófilo/lipófilo (HLB).

Os testes de solubilidade em água evidenciaram qualitativamente a variação do caráter hidrófilo, porém não apresentaram uma relação quantitativa entre a solubilidade e o teor de segmento hidrófobo incorporado. Os testes de solubilidade em DMF em função da temperatura foram eficientes para estabelecer uma relação entre o teor de grupamentos hidrófobos e a temperatura de solubilização.

A solubilidade dos polímeros decresce com o aumento do teor de segmento hidrófobo incorporado. Um maior número de segmentos hidrófobos curtos, distribuídos ao longo da cadeia de polímero, pode ser responsável por uma maior modificação no HLB, quando comparado com moléculas possuindo segmentos longos presentes em menor quantidade.

A determinação da tensão superficial das soluções não foi uma técnica eficiente para avaliar a variação da atividade superficial. Não foi observada variação a tensão superficial das soluções aquosas em função da pequena incorporação de grupo hidrófobo, a qual ainda mantém o polímero solúvel em água.

\section{Agradecimentos}

As autoras agradecem ao Conselho Nacional de Desenvolvimento Científico e Tecnológico (CNPq) pelo financiamento da pesquisa e ao CENPES/ PETROBRAS pela utilização do tensiômetro.

\section{Referências bibliográficas}

1. Yahya, G. O.; Asrof Ali, S. K.; Al-Naafa, M. A. \& Hamad, E. Z. - J. Appl. Polym. Sci., 57, p.343 (1995).

2. Wang, Y. F.; Chen, T. M.; Li, Y. J.; Kitamura, M. \& Nakaya, T. - Macromolecules, 29, p.5819 (1996).

3. Wang, S. E.; Fang, T. R.; Li, Y.; Zhang, H. F. \& Mo, Z. S. - Polym Bull., 35, p.351 (1995).

4. Marten, F. L. - "Vinyl alcohol polymers", in: Encyclopedia of Polymer Science and Engineering, vol. 17, H. F. Mark, N. M. Bikales, C. G. Overberger \& G. Menges (eds.), John-Wiley, New York (1985). 
5. Okaya, T.; Suzuki, A. \& Kikuchi, K. - Coll. And Surf. A: Physicochem and Eng. Asp., 153, p.123 (1999).

6. Liu, J. H.; Chung, Y. C. \& Li, M. T. - J. Appl. Polym. Sci., 55, p.1441 (1995).

7. Batyrbekov, E. O.; Iskakov, R. \& Zhubanov, B. A. Makromol. Symp., 127, p.251 (1998).

8. Finch, C. A. - "Poly Vinyl Alcohol, Properties and Applications”, John-Wiley, New York (1973).

9. Saunders, K. J. - "Organic Polymer Chemistry", Chapman and Hall, London (1973).

10. Cowie, J. M. G. - "Polymers: Chemistry \& Physics of Modern Materials”, Chapman and Hall, Ney York, $2^{a}$ edição (1991).
11. Brandrup, J. \& Immergut, E. H. - "Polymer Handbook”, John-Wiley, New York, $3^{a}$ edição, p. VII/12 (1989).

12. Morrison, R. T. \& Boyd, R. N. - "Organic Chemistry", Prentice Hall, New Jersey, $6^{\text {th }}$ edition (1992).

13. Lide, D. R. - "Handbook of Chemistry and Physics", The Chemical Rubber Co., Flórida, $76^{a}$ edição (1995).

14. Brandrup, J. \& Immergut, E. H. - "Polymer Handbook", John-Wiley, New York, $3^{a}$ edição, p. VII/554 (1989).

Recebido: 02/05/01

Aprovado: 15/11/01 